\title{
Influence of power and maximal strength training on thermal reaction and vertical jump performance in Brazilian basketball players: a preliminary study
}

\author{
Jaime Della Corte ${ }^{1,2}$, Wendell Luiz M. Pereira ${ }^{3}$, Eduardo Emil Lacerda S. Corrêa ${ }^{3}$, João Gabriel \\ Miranda de Oliveira ${ }^{2,3}$, Bruno Lucas Pinheiro Lima ${ }^{2,4}$, Juliana Brandão Pinto de Castro ${ }^{2,4,5}$, Vicente \\ Pinheiro Lima ${ }^{1,2,3,4,5}$
}

1 Postgraduate Program in Human Anatomy and Biomechanics, Castelo Branco University, Rio de Janeiro, Brazil; 2 Research Group of Performance, Biodynamics, Exercise, and Health (BIODESA), Castelo Branco University, Rio de Janeiro, Brazil; ${ }^{3}$ Faculty of Physical Education, Castelo Branco University, Rio de Janeiro, Brazil; 4 Postgraduate Program in Exercise and Sport Sciences, Institute of Physical Education and Sports, Rio de Janeiro State University, Rio de Janeiro, Brazil; ${ }^{5}$ Laboratory of Exercise and Sport (LABEES), Rio de Janeiro State University, Rio de Janeiro, Brazil

\section{Summary}

Study aim: To evaluate the effect of power and muscle strength training on skin temperature and the performance of the vertical jump with countermovement (CMJ).

Material and methods: The sample consisted of four male basketball athletes of the under-17 category (age: $15.75 \pm 1.0$ years). 48 hours after anthropometric evaluation and determination of the loads for 1 repetition maximum (1RM) in the leg extension exercise, the athletes were subjected, through crossover-type entrance, to power (PTP) and strength (STP) training protocols. The protocols consisted of three sets with loads of $60 \%$ and $90 \%$ of 1RM for PTP and STP, respectively. Thermographic images of the thighs were taken before and immediately after each training session.

Results: There were significant differences in results between the two training protocols, with increased total repetitions $(\mathrm{t}=13.481 ; \mathrm{p}<0.05)$ and total training volume $(\mathrm{t}=15.944 ; \mathrm{p}<0.05)$ in the PTP, and increase in the $\%$ of $1 \mathrm{RM}$ $(t=33.903 ; p<0.05)$ and rating of perceived exertion $(t=6.755 ; p<0.05)$ in the STP. The skin temperature before and after PTP and STP showed no significant differences. In the post-STP, the CMJ presented significant reductions in height $(\mathrm{t}=3.318 ; \mathrm{p}<0.05)$, flight time $(\mathrm{t}=3.620 ; \mathrm{p}<0.05)$, velocity $(\mathrm{t}=3.502 ; \mathrm{p}<0.05)$, and force $(\mathrm{t}=4.381 ; \mathrm{p}<0.05)$. There were no significant differences in pre-and post-STP CMJ.

Conclusions: Power and maximum strength training in the leg extension exercise performed until concentric failure appears to be a method that induces thermal stress on the skin. This training directly influenced the performance of the vertical jump after the stimulus.

Keywords: Resistance training - Thermography - Muscle strength - Elastic energy

\section{Introduction}

Basketball is a high-intensity intermittent sport. Due to the game dynamics, the players must achieve good physical fitness through training sessions focused on improving endurance, speed, power, and muscle strength [15]. Resistance training (RT) has become one of the most popular forms of exercise for improving fitness. It is recommended for athletes and recreational RT practitioners [17].
The production of muscle strength is the ability of the muscle to be in a state of active tension through a contraction, regardless of the amount of force that is applied to overcome a load [11]. However, RT performed at a high frequency of movement causes the recruited muscles to contract faster compared to voluntary contraction using higher loads. Training with high-speed muscle contraction is one of the main methods used to increase explosive strength and efficiency in vertical jump performance $[27,45]$. 
Another element that promotes evolution in vertical jump performance is the refinement of the movement mechanics technique by increasing the number of repetitions of this motor gesture [37]. The greater the mastery of the vertical jump technique, the better tends to be its performance, directly influencing the improvement of the motor movement technique $[2,9]$.

To improve vertical jump performance, power and muscle strength training should be practiced in low-repetition training sessions and on alternate days. However, when practiced on the same day, they may induce a greater increase in muscle fibers and, consequently, increase strength and muscle hypertrophy $[38,46]$.

Depending on the effort inherent to the RT performed before the jumps, the muscles involved in physical exercises may be equally fatigued and empowered. Hence, the effectiveness of the explosive activity will be determined by the ability to recover glycogen stores without dissipation of the empowered effects [47].

However, it is worth mentioning that excessive training loads, as well as the game itself, can cause injuries [26] and overload-related stresses that can lead to the overtraining syndrome. This can decrease players' performance [31] and affect their ability to participate in training sessions and games $[14,40]$.

In this sense, the use of the infrared thermal camera has been a useful device of analysis, which can help to observe some abnormalities, asymmetries or blood circulation disorders before or after a training session. The utilization of this equipment has been growing significantly in recent years in the sports field $[3,5]$. Thermography is able to monitor risks and track injuries, as well as being an important tool in the follow-up of the RT, from the evaluation and quantification of training loads [8].

As seen, there is evidence of the effects of RT on the vertical jump. Nevertheless, there is still a need for further investigations on the influence of different training methods, considering the possibility of assessing muscle temperature through thermographic imaging as a marker of tissue stress level. Therefore, the present study aimed to analyze the effect of power and muscle strength training on skin temperature and vertical jump performance.

\section{Material and methods}

\section{Participants}

This research was conducted using a crossover-randomized design. The sample was selected intentionally and non-probabilistically, being composed of four male basketball athletes of the under-17 category of a club in the south zone of Rio de Janeiro, Brazil. The inclusion criteria were: a) federated athletes of the referred modality for at least 2 months, who regularly compete in the State
Championship; b) RT practitioners with at least six months of experience; c) a minimum weekly training frequency of two sessions. The exclusion criteria were: a) all individuals with degenerative or metabolic diseases; b) those who had any bone, muscle or joint injuries or limitations that made it impossible to perform the programmed exercises; c) those using ergogenic substances; and d) those who responded positively to the Physical Activity Readiness Questionnaire (PAR-Q) [1].

The present study was performed in accordance with Resolution 510/2016 of the National Health Council of Brazil and the Declaration of Helsinki. The participants' guardians and the participants signed an informed consent form prior to taking part in the study.

\section{Procedures}

Data collection occurred through three non-consecutive visits, which were always at the same time and at least 48 hours apart. At the first visit, the volunteers were informed about all data collection and study intervention procedures and those responsible for the volunteers signed the informed consent form. The participants signed the informed consent form and answered the PAR-Q questionnaire, performed anthropometric measurements and the one-repetition maximum (1RM) tests. At the second visit, the individuals were submitted to the $1 \mathrm{RM}$ retest. At the third visit, the athletes performed alternately in crossover the sessions of power and muscle strength training until the concentric failure, the thermographic images and the vertical jump measurements, respectively, being collected before and after the RT (Fig. 1).

The participants were instructed not to exercise at all and not to take stimulant substances in the 24 hours prior to both data collection and intervention. All tests, retests and training sessions were conducted at times similar to those of volunteer training and at controlled room temperature.

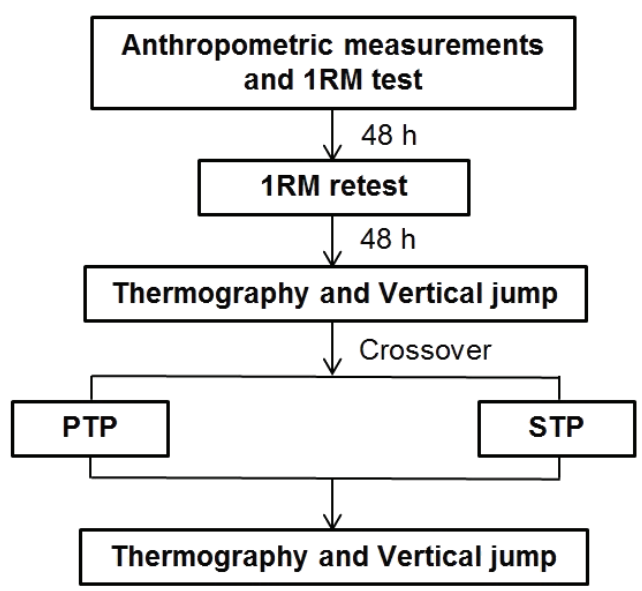

Fig. 1. Schematic model of the research 1RM: one-repetition maximum test; PTP: Power training protocol; STP: Strength training protocol. 


\section{Anthropometric measurements}

To characterize the sample, height was determined using a Cardiomed stadiometer (WCS model, Brazil), with a maximum capacity of $2.20 \mathrm{~m}$. Weight was measured using the OMRON scale (Full Body Sensor, model HBF514C, USA) with $100 \mathrm{~g}$ accuracy. Body mass index (BMI) was calculated as the ratio between weight $(\mathrm{kg})$ and height squared $\left(\mathrm{m}^{2}\right)$. All measurements followed the specific protocols suggested by the International Standards for Anthropometric Assessment (International Society for the Advancement of Kinanthropometry, ISAK) [29].

\section{One repetition maximum test (1RM)}

In order to verify the training load and exercise prescription criteria, we applied the 1RM test, following the protocol recommended by Brown [7]. The test was performed on the leg extension exercise (Technogym, Life Fitness model, USA). The 1RM tests were performed in a single day, adopting the following procedures: 1) start a warm-up set with a load low enough to easily perform five to ten repetitions; 2 ) one-minute rest; 3) perform another warm-up set with a load that allows three to five repetitions to be completed, which usually means increasing about 4.5 to $9 \mathrm{~kg}$ or $5-10 \%$ of the previous load; 4) rest of two minutes; 5) calculate another increase of 4.5 to $9 \mathrm{~kg}$ or 5 to $10 \%$ that allows two to three repetitions to be completed; 6) rest for two to four minutes; 7) estimate another increase of 4.5 to $9 \mathrm{~kg}$ or 5 to $10 \%$ that allows only one repetition with the exercise performed in the correct form. Being able to complete the repetition, move on to step 8 , otherwise, skip to step $9 ; 8$ ) rest for two to four minutes, calculate another moderate increase in load (4.5 to $9 \mathrm{~kg}$ or 5 to $10 \%$ ) and repeat the test; 9) if the individual is not able to complete properly, rest for two to four minutes, reduce the load by 2.3 to $4.5 \mathrm{~kg}$ and repeat. Continue increasing or reducing the load as needed until the actual load to 1RM is determined. If the load is not found within five attempts after completing the warm-up sets, a new test day was performed 48 hours apart between attempts.

The load recorded was determined from the maximum obtained for 1RM. After resting for at least 48 hours, to obtain reproducibility of the loads, the volunteers were submitted to retesting following the same procedures described above. The highest load established on both days was considered the 1RM [42], provided that the difference between them was not greater than 5\%. However, if the stipulated percentage was exceeded, retesting and retesting were scheduled.

In order to reduce the margin of error in testing and retesting, the following strategies were adopted [33]: a) standardized instructions were provided prior to testing so that the subject was aware of the entire routine involving data collection; b) the participant was instructed about the technique of execution of the exercise; c) the evaluators were aware of the position adopted by the participant at the time of the measurement, as small variations in the positioning of the joints involved in the movement could trigger other muscles, leading to misinterpretation of the scores obtained; and d) verbal stimuli were performed in order to keep the stimulation at a high level.

For a better description of the movement, the initial position was established with the subject sitting in the extension chair with the knees at $90^{\circ}$ of flexion and its articular axis aligned with the equipment axis, foot support on the anterior aspect of the distal third of the legs, and all plates (loads) should be overlapping. The final position was considered as the complete knee extension, i.e. the ability to lift the determined load until the knee joint reached $0^{\circ}$. For standardization purposes, the initial position was delimited by the moment of touch of the plates and the final position by the touch of the bar of the device on an elastic cord placed for reference. Amplitudes were previously measured by a steel goniometer with $360^{\circ}$ of amplitude.

The execution speed of the movement was as fast as possible, not being allowed to exceed two seconds for the concentric phase and two seconds for the eccentric phase. Validation took place under the following criteria [12]: a) no interval was allowed between the concentric and eccentric phases; b) the repetitions that did not fit the pre-established technical standards were not accounted for. The tests were interrupted when the subjects could not perform the programmed movement correctly and/or completely, voluntary concentric failure occurring.

\section{Thermographic images}

The infrared image capture protocol was performed according to the recommendations of the Consensus Thermographic Imaging in Sports and Exercise Medicine (TISEM) [34]. The camera used was the Forward-Looking Infra-Red (FLIR) (FLIR ONE Pro iOS model, Wilsonville, OR, USA) [22] coupled with an Apple smartphone (iPhone 6 model, Cupertino, USA). FLIR ONE Pro iOS is capable of detecting temperatures with dynamic scene ranges between $-20^{\circ}$ and $400^{\circ} \mathrm{C}$, has an accuracy of $\pm 3^{\circ} \mathrm{C}$ or $\pm 5 \%$, with a typical percentage of differences between ambient and scene temperature. It includes two cameras, one with a Lepton thermal sensor, $12 \mu \mathrm{m}$ pixel size and 8 to $14 \mu \mathrm{m}$ spectral range, and the other with a high definition Video Graphics Array (VGA), $160 \times 120$ pixels. Thus, two images are obtained which are merged by the Multi-Spectral Dynamic Imaging (MSX) technology, which superimposes a thermal image on a photographic image, enriching the images with perigrams in the areas of interest, resulting in a thermographic image with a visual resolution of $1440 \times 1080$ pixels.

In order for the results to be less influenced by possible external factors, some precautions were taken before obtaining the thermographic images. Thus, participants were instructed as follows [35]: 1) to avoid sun exposure or ultraviolet rays in the hours between $10 \mathrm{~h}$ and $16 \mathrm{~h}$ in the 24 hours 
prior the tests; 2) not to perform vigorous physical exercises in the last 24 hours; 3 ) not to do any massage therapy treatment in the last 24 hours; 4) not to drink alcohol or caffeinated drinks in the last 6 hours; 5) not to take a hot or very cold shower minutes before the evaluation; 6) not to apply cream, gel or any other cosmetic products on the skin; and 7) wear appropriate clothing (shorts or swimming trunks).

The software used for the analysis of the thermal images of the anterior part of the athletes' thighs was FLIR Tools, which allows one to quickly import, edit and analyze images and turn them into professional inspection reports. The app allows one to thermally tune level and span, change the color palette, and adjust parameters such as emissivity and reflective temperature.

\section{Vertical countermovement jumps}

The vertical thrust test was performed with the MyJump2 app $[18,19]$ developed for Apple, which presents reliable and validated features for a vertical jump with countermovement (CMJ) measurement. CMJ involves a pattern of muscle function called the stretching/shortening cycle, which occurs when a basic flexion movement of the hips, knees, and dorsiflexion is performed with subsequent extension of hip and knees, and plantar flexion movements in the eccentric and concentric action cycle, respectively [24].

MyJump2 analyzes countermovement jumps from video capture. Application algorithms, using specific equations [6,44], provide the calculation of the maximum CMJ height in centimeters $(\mathrm{cm})$, the CMJ flight time in milliseconds (ms), the CMJ velocity, in meters per second $(\mathrm{m} / \mathrm{s})$, the $\mathrm{CMJ}$ force in newtons $(\mathrm{N})$, and the CMJ power peak in watts (W). For this, the researcher must identify in the app the takeoff and landing frames that will be analyzed.

Before CMJ measurements were recorded, the following data from the participants were entered in the application: 1) weight $(\mathrm{kg})$; 2) length of the lower limbs (cm), measured from the distance from the greater trochanter of the femur to the most distal point of the hallux, as assessed in the supine position, keeping the talocrural joint in plantar flexion; and 3) height (cm) at $90^{\circ}$, as measured by the vertical distance between the greater femoral trochanter and the ground in an ideal knee flexion position to perform the highest possible jump (knee angle around $90^{\circ}$ ).

\section{Training protocol}

The power training protocol (PTP) and the strength training protocol (STP) consisted of performing one training session with three sets of maximal repetitions (up to concentric failure) in the leg extension exercise with loads of $60 \%$ and $90 \%$ of $1 \mathrm{RM}$, respectively [25].

\section{Training session}

Participants underwent lower limb training sessions, which consisted of a specific warm-up $[32,41]$ of one set of 12 repetitions in the leg extension exercise with $50 \%$ of $1 \mathrm{RM}$. The training protocols were performed two minutes after warm-up, through alternate crossover input. The distinct protocols were performed on the same day with a minimum interval of 30 minutes between them.

During the sets, subjects were encouraged to exhale in the concentric phase and inhale in the eccentric phase of the movement, avoiding the Valsalva maneuver. The required movement execution speed was the same as for tests and retests (maximum time of two seconds for the concentric phase and two seconds for the eccentric phase). Passive intervals between sets were three minutes. At the end of the training session, participants indicated the rating of perceived exertion (RPE), according to the OMNI scale [36].

The researchers captured the thermal images from an angle perpendicular to the research area at a distance of 100 to $150 \mathrm{~cm}$. Images were taken before and immediately after each training session (Fig. 2). Before the thermographic images of the anterior part of thighs were recorded, the participants remained sitting at rest for at least 15 minutes in an air-conditioned room with digital temperature and humidity control.

To ensure correct measurements, external heat sources were switched off. Moreover, in order to measure and ensure the stability of the temperature and humidity of the environment, two digital thermohygrometers (model AK27new, Akso, Brazil) were placed in the intervention room. The average room temperature was maintained at $20.4 \pm 0.4^{\circ} \mathrm{C}$, with an average relative humidity of $54.8 \pm 1.6 \% \mathrm{RH}$.

Videos for CMJ analysis before and after each training session were obtained subsequent to the capture of thermographic images. The evaluators were positioned in the frontal plane at a maximum distance of $150 \mathrm{~cm}$ from the subject with the camera positioned towards the participant's feet. At the command of the evaluators, the subject squats, with the hands on the waist, jumps, and lands on the ground. The evaluators select the images of the jump counting from the moment the subject's feet leave the ground until he touches the ground again [4].

\section{Statistical analysis}

Data were processed using the software SPSS 22.0 (Chicago, IL, USA) and presented with a descriptive analysis of mean, standard deviation, and minimum and maximum values. The normality and homogeneity of the sample data were verified with the Shapiro-Wilk and Levene tests, respectively. To analyze the differences between training protocols, the paired Student t-test was applied. To verify the skin temperature behavior and the jump performance after the training sessions of the different protocols, the paired Student $\mathrm{t}$-test and the percentage difference were applied. The significance level adopted was $\mathrm{p}<0.05$. 

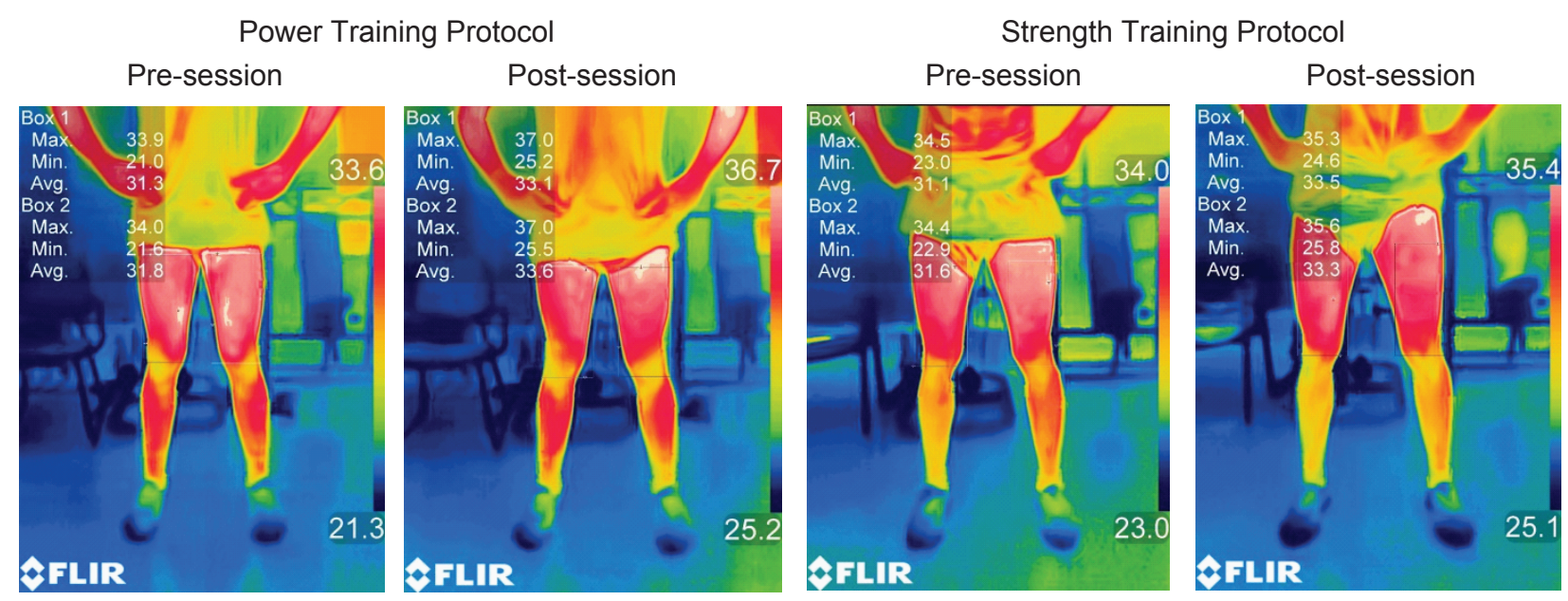

Fig. 2. Thermographic images

\section{Results}

Table 1 shows the participants' data on body composition and the ratio between the maximum 1RM load and total body mass.
Table 2 presents the data regarding the participants' training sessions. There were significant differences in the results between the two training protocols (PTP and STP) with increases in the values of the total RM $(\mathrm{t}=13.481$; $\mathrm{p}<0.05)$ and TTV $(\mathrm{t}=15.944 ; \mathrm{p}<0.05)$ in the PTP and increases in the values of the variables $\%$ of $1 \mathrm{RM}$

Table 1. Body composition and 1RM/TBM ratio of the sample

\begin{tabular}{lcccccc}
\hline & Age [years] & Height $[\mathrm{m}]$ & TBM $[\mathrm{kg}]$ & BMI $\left[\mathrm{kg} / \mathrm{m}^{2}\right]$ & 1RM $[\mathrm{kg}]$ & 1RM/TBM [\%] \\
\hline Mean & 15.75 & 1.90 & 84.2 & 23.26 & 144.8 & 175.0 \\
SD & 1.0 & 0.1 & 12.6 & 1.8 & 8.5 & 28.6 \\
Minimum & 15 & 1.85 & 75.1 & 21.94 & 136.0 & 138.1 \\
Maximum & 17 & 1.99 & 102.1 & 25.78 & 156.0 & 207.7 \\
p-value (SW) & 0.272 & 0.183 & 0.171 & 0.206 & 0.850 & 0.836 \\
\hline
\end{tabular}

$\mathrm{SD}$ - standard deviation; TBM - total body mass; BMI - body mass index; 1RM - maximum load obtained in the 1RM test; 1RM/TBM - ratio of the maximum load obtained by the total body mass; p-value (SW) - Shapiro-Wilk normality test.

Table 2. Training session results

\begin{tabular}{|c|c|c|c|c|}
\hline \multicolumn{5}{|c|}{ Power Training Protocol } \\
\hline & $60 \%$ of $1 \mathrm{RM}[\mathrm{kg}]$ & Total RM & TTV $[\mathrm{kg}]$ & RPE (0 to 10$)$ \\
\hline Mean & 86.9 & 63.5 & 5498.9 & 5.3 \\
\hline SD & 5.1 & 7.0 & 466.2 & 1.0 \\
\hline \multicolumn{5}{|c|}{ Strength Training Protocol } \\
\hline & $90 \%$ of $1 \mathrm{RM}[\mathrm{kg}]$ & Total RM & TTV $[\mathrm{kg}]$ & RPE (0 to 10$)$ \\
\hline Mean & 130.3 & 10.0 & 1317.4 & 9.5 \\
\hline SD & 7.7 & 2.9 & 465.8 & 0.6 \\
\hline $\mathrm{p}$-value (t-test) & $0.0001 *$ & $0.001 *$ & $0.001 *$ & $0.007^{*}$ \\
\hline
\end{tabular}

$90 \%$ of 1 RM - workload; total RM - total repetition maximum (sets $\times$ repetitions); TTV - total training volume (exercises $\times$ load $\times$ sets $\times$ repetitions); RPE - rating of perceived exertion; $60 \%$ of $1 \mathrm{RM}$ - workload; p-value (t-test) - paired Student t-test; * - significant difference between protocols. 
Table 3. Power Training Protocol (PTP)

\begin{tabular}{|c|c|c|c|c|c|c|}
\hline \multicolumn{7}{|c|}{ Pre-PTP } \\
\hline & \multicolumn{2}{|c|}{ Skin temperature } & \multicolumn{4}{|c|}{$\mathrm{CMJ}$} \\
\hline & Maximum $\left[{ }^{\circ} \mathrm{C}\right]$ & Minimum $\left[{ }^{\circ} \mathrm{C}\right]$ & Height $[\mathrm{cm}]$ & Flight [ms] & Velocity [m/s] & Force $[\mathrm{N}]$ \\
\hline Mean & 30.1 & 21.4 & 32.36 & 506.25 & 1.24 & 1843.52 \\
\hline $\mathrm{SD}$ & 3.1 & 3.4 & 11.1 & 99.2 & 0.2 & 137.3 \\
\hline \multicolumn{7}{|c|}{ Post-PTP } \\
\hline & Maximum $\left[{ }^{\circ} \mathrm{C}\right]$ & Minimum $\left[{ }^{\circ} \mathrm{C}\right]$ & Height $[\mathrm{cm}]$ & Flight [ms] & Velocity [m/s] & Force $[\mathrm{N}]$ \\
\hline Mean & 35.0 & 26.7 & 24.73 & 442.75 & 1.09 & 1610.54 \\
\hline SD & 0.7 & 0.8 & 9.0 & 86.3 & 0.2 & 141.1 \\
\hline $\mathrm{p}$-value (t-test) & 0.056 & 0.062 & $0.045^{*}$ & $0.036^{*}$ & $0.039 *$ & $0.022 *$ \\
\hline \multicolumn{7}{|c|}{ Percentage difference between pre and post-PTP } \\
\hline & Maximum $\left[{ }^{\circ} \mathrm{C}\right]$ & Minimum $\left[{ }^{\circ} \mathrm{C}\right]$ & Height $[\mathrm{cm}]$ & Flight [ms] & Velocity $[\mathrm{m} / \mathrm{s}]$ & Force $[\mathrm{N}]$ \\
\hline $100 \%$ & 65.1 & 48.1 & 57.09 & 949.00 & 2.33 & 3454.06 \\
\hline Pre $\%$ & 46.2 & 44.5 & 56.68 & 53.35 & 53.22 & 53.37 \\
\hline Post \% & 53.8 & 55.5 & 43.32 & 46.65 & 46.78 & 46.63 \\
\hline$\%$ difference & 7.6 & 11.0 & -13.36 & -6.70 & -6.44 & -6.74 \\
\hline
\end{tabular}

CMJ - countermovement jump; p-value (t-test) - paired Student t-test; * - significant difference between pre- and post-PTP.

Table 4. Strength Training Protocol (STP)

\begin{tabular}{|c|c|c|c|c|c|c|}
\hline \multicolumn{7}{|c|}{ Pre-STP } \\
\hline & \multicolumn{2}{|c|}{ Skin temperature } & \multicolumn{4}{|c|}{$\mathrm{CMJ}$} \\
\hline & Maximum $\left[{ }^{\circ} \mathrm{C}\right]$ & Minimum $\left[{ }^{\circ} \mathrm{C}\right]$ & Height $[\mathrm{cm}]$ & Flight $[\mathrm{ms}]$ & Velocity $[\mathrm{m} / \mathrm{s}]$ & Force $[\mathrm{N}]$ \\
\hline Mean & 31.9 & 21.6 & 28.79 & 479.00 & 1.18 & 1756.37 \\
\hline SD & 2.0 & 1.8 & 9.3 & 82.3 & 0.2 & 213.1 \\
\hline \multicolumn{7}{|l|}{ Post-STP } \\
\hline & Maximum $\left[{ }^{\circ} \mathrm{C}\right]$ & Minimum $\left[{ }^{\circ} \mathrm{C}\right]$ & Height $[\mathrm{cm}]$ & Flight $[\mathrm{ms}]$ & Velocity $[\mathrm{m} / \mathrm{s}]$ & Force $[\mathrm{N}]$ \\
\hline Mean & 34.6 & 24.5 & 29.37 & 483.75 & 1.19 & 1767.15 \\
\hline SD & 2.7 & 2.0 & 9.5 & 86.4 & 0.2 & 195.6 \\
\hline $\mathrm{p}$-value (t-test) & 0.111 & 0.152 & 0.694 & 0.699 & 0.692 & 0.805 \\
\hline \multicolumn{7}{|c|}{ Percentage difference between pre and post-STP } \\
\hline & Maximum $\left[{ }^{\circ} \mathrm{C}\right]$ & Minimum $\left[{ }^{\circ} \mathrm{C}\right]$ & Height $[\mathrm{cm}]$ & Flight [ms] & Velocity $[\mathrm{m} / \mathrm{s}]$ & Force $[\mathrm{N}]$ \\
\hline $100 \%$ & 66.5 & 46.1 & 58.16 & 962.75 & 2.37 & 3523.52 \\
\hline Pre \% & 48.0 & 46.9 & 49.50 & 49.75 & 49.79 & 49.85 \\
\hline Post \% & 52.0 & 53.1 & 50.50 & 50.25 & 50.21 & 50.15 \\
\hline$\%$ difference & 4.0 & 6.2 & 1.00 & 0.50 & 0.42 & 0.30 \\
\hline
\end{tabular}

$\mathrm{CMJ}$ - countermovement jump; $\mathrm{p}$-value (t-test) - paired Student t-test.

$(\mathrm{t}=33.903 ; \mathrm{p}<0.05)$ and $\operatorname{RPE}(\mathrm{t}=6.755 ; \mathrm{p}<0.05)$ in the STP.

Tables 3 and 4 show the pre and post values of each training protocol. It was observed that there were no significant differences in the maximum and minimum temperatures of the anterior part of the thighs between the pre - and post-training of each protocol. Regarding CMJ, significant differences occurred with reduction of height $(\mathrm{t}=3.318 ; \mathrm{p}<0.05)$, flight $(\mathrm{t}=3.620 ; \mathrm{p}<0.05)$, velocity $(\mathrm{t}=3.502 ; \mathrm{p}<0.05)$ and force $(\mathrm{t}=4.381 ; \mathrm{p}<0.05)$ after 
Table 5. Percentage difference of PTP and STP protocols after each training session

\begin{tabular}{lllllll}
\hline & Maximum $\left[{ }^{\circ} \mathrm{C}\right]$ & Minimum $\left[{ }^{\circ} \mathrm{C}\right]$ & Height $[\mathrm{cm}]$ & Flight $[\mathrm{ms}]$ & Velocity $[\mathrm{m} / \mathrm{s}]$ & Force $[\mathrm{N}]$ \\
\hline Dif. PTP & 7.6 & 11.0 & -13.36 & -6.70 & -6.44 & -6.74 \\
Dif. STP & 4.0 & 6.2 & 1.00 & 0.50 & 0.42 & 0.30 \\
\hline
\end{tabular}

Dif. PTP - Power Training Protocol percentage difference; Dif. STP - Strength Training Protocol percentage difference.

the training session. There were no significant differences in the skin temperature in the CMJ after the training session.

Table 5 presents the results of the percentage difference in the skin temperature of the anterior part of the thighs and the $\mathrm{CMJ}$ between the training protocols.

\section{Discussion}

This study aimed to analyze the influence of power and muscle strength training on the thermal responses of the anterior part of thighs and the vertical jump performance of male basketball athletes in the leg extension exercise performed until concentric failure.

According to the results obtained when comparing the two protocols (PTP versus STP) after the training sessions, significant differences of the results were observed in the PTP, which even though presenting lower means for the values of $\%$ of $1 \mathrm{RM}$ and RPE, showed an increase of total RM and TTV. Thus, the PTP presented a lower average for the workload $(86.9 \mathrm{~kg})$ and RPE (5.3 = somewhat hard), but a higher mean number of maximum repetitions (63.5) and $\operatorname{TTV}(5,498.9 \mathrm{~kg})$.

The percentage difference between pre- and postPTP showed an acute increase in the maximum $\left(7.6^{\circ} \mathrm{C}\right)$ and minimum $\left(11.0^{\circ} \mathrm{C}\right)$ temperature of the analyzed muscle group and a decrease in CMJ performance at height $(-13.36 \mathrm{~cm})$, time $(-6.70 \mathrm{~ms})$, velocity $(-6.44 \mathrm{~m} / \mathrm{s})$, and force $(-6.74 \mathrm{~N})$. This led to significant differences with reduced values of the variables height, flight time, velocity and force after the training session.

Similarly, the percentage difference between pre and post-STP also showed an acute increase in maximum $\left(4.0^{\circ} \mathrm{C}\right)$ and minimum $\left(6.2^{\circ} \mathrm{C}\right)$ temperatures, but a small non-significant improvement in $\mathrm{CMJ}$ performance at height $(1.00 \mathrm{~cm})$, flight time $(0.50 \mathrm{~ms})$, velocity $(0.42 \mathrm{~m} / \mathrm{s})$, and force $(0.30 \mathrm{~N})$.

Côrte and Hernandez [10] state that the use of the thermographic camera in sports is a useful tool and can diagnose and prevent injuries, playing an important role in the quantification of training load. Furthermore, it is a safe and non-invasive method.
The thermal responses depend on a series of specific physiological adjustments, such as body homeostasis and physical health of the individual. Thermography is important in sport, as it enables the athlete to provide feedback about the performance through a quick qualitative and quantitative assessment [30]. During RT, metabolism increases to meet physiological needs, causing changes in body temperature. Such changes generate heat [43]. The decrease in central temperature occurs gradually after a long period of exercise completion [16].

Oliveira et al. [39] observed that progressive exercises performed to exhaustion promote more significant increases in body temperature values than exercises that are not performed in such a way. This corroborates the findings of the present study, as the temperature in the observed areas increased in both PTP and STP. However, the temperature was higher in PTP, probably due to the milder PTP load compared to STP. This may have contributed to the participants being able to perform the exercise until concentric failure an average of six times the number of maximum repetitions and four times more in the TTV.

On the other hand, Della Corte et al. [13] verified the skin temperature of the anterior thighs of ten recreationally trained men, with an average age of $24.0 \pm 2.7$ years, after performing five unilateral sets with the dominant side of the lower limb, in the leg extension exercise with $70 \%$ of $10 \mathrm{RM}$. The study concluded that there were no significant changes in the temperature of the area of interest immediately after the training session, possibly because the individuals analyzed were already experienced RT practitioners. Therefore, it is possible that the individuals recruited more synergistic muscles to perform the same movement, requiring fewer of the agonist muscles.

Hester et al. [20] submitted 14 men with experience in RT (age: $22 \pm 2.1$ years) to two protocols in order to observe the acute effect of training sessions on vertical jump performance. Subjects performed vertical jumps with countermovement before and 1, 3, 5, and 10 minutes after the training sessions. The fast jump squat protocol consisted of 10 repetitions at $20 \%$ of 1 RM and the high load jump squat consisted of 5 repetitions at $80 \%$ of 1 RM. 
Height $(\mathrm{cm})$, output power $(\mathrm{W})$, and velocity $(\mathrm{m} / \mathrm{s})$ of the jumps were recorded using the JumpMat equipment through a linear transducer. The results showed that there was no improvement in vertical jump performance after both protocols at any recovery interval.

Similarly, Jones and Lees [23] investigated the performance of $\mathrm{CMJ}$ in eight men (age: $23.6 \pm 3.4$ years) experienced in resistance and plyometric training, practitioners of sports activities (running, basketball, rugby, and football), after five repetitions of squats on the smith machine with loads of $85 \%$ 1RM. When comparing the results of the variables maximum height $(\mathrm{cm})$, takeoff velocity $(\mathrm{m} / \mathrm{s})$, vertical force $(\mathrm{N})$, and peak power $(\mathrm{W})$ of the CMJ after 3,10 , and 20 minutes of recovery with the measured results in the pre-training session, they found no significant differences in any of the variables at any time, tending to either remain or decrease.

Previous studies have emphasized that exercises performed to concentric failure exhaustively, with the same movement pattern, may provide reflex changes that cause decreased vertical jump performance $[21,28]$. This way, it is understood that the vertical thrust performance that underwent acute reduction after the power training session of the present study is normal and even consistent when compared with the RT session.

There are some limitations in this study that should be mentioned. Due to the small sample size, the obtained results should be interpreted with caution. Additionally, temperature behavior and jump performance were verified subsequent to training protocols. Adding recovery intervals after training sessions could lead to other outcomes.

\section{Conclusions}

It was concluded that the power and muscle strength training prescribed in the present study with the volume and intensity characteristics in the leg extension exercise performed until concentric failure seems to be a tissue stress method that increases local skin temperature and reduces vertical jump performance. However, STP, when compared to PTP, had a less negative impact on performance. This condition demonstrates that care should be taken when practicing these types of training with subsequent technical and tactical training, and games, as they affect the performance of athletes. It is suggested that further investigations be conducted with a larger number of participants, of both sexes, of different ages, with different levels of physical fitness, and with different training methods and physical exercises.

Conflict of interest: Authors state no conflict of interest.

\section{References}

1. American College of Sports Medicine (2014) ACSM's guidelines for exercise testing and prescription. $9^{\text {th }}$ ed. Philadelphia: Wolters Kluwer; Lippincott Williams \& Wilkins.

2. Andrade R.M., Amadio A.C., Serrăo J.C., Kiss M.A., Moreira A. (2012) Contribution of biomechanical parameters to vertical jump performance in basketball players. Rev. Bras. Med. Esporte, 26(2): 181-192. DOI: 10.1590/ S1807-55092012000200002.

3. Araújo V.A., Carvalho L.S., Morais N.A., Souza E.S., Santos R.M., Silva F.J. (2018) Thermographic analysis of lower limbs of young assets after an acute plyometric training session. Revista Brasileira de Prescriçăo e Fisiologia do Exercício, 72(12): 56-62.

4. Balsalobre-Fernández C., Glaister M., Lockey R.A.(2015) The validity and reliability of an iPhone app for measuring vertical jump performance. J. Sports. Sci., 33(15): 1574-1579. DOI: 10.1080/02640414.2014.996184.

5. Bandeira F., Neves E.B., Moura M.A., Nahoma P. (2014) The thermography in support for diagnosis of muscle injury in sport. Rev. Bras. Med. Esporte, 20(1): 59-64. DOI: 10.1590/S1517-86922014000100012.

6. Bosco C., Luhtanen P., Komi P.V. (1983) A simple method for measurement of mechanical power in jumping. Eur. J. Appl. Physiol. Occup. Physiol., 50(2): 273-282. DOI: $10.1007 / \mathrm{bf00422166.}$

7. Brown L.E. (2017) Strength Training. National Strength and Conditioning Association. $2^{\text {nd }}$ ed. Champaign, IL: Human Kinetics.

8. Brukner P., Khan K (2011) Brukner and Khan's Clinical Sports Medicine. $4^{\text {th }}$ ed. Sydney: McGraw-Hill Australia.

9. Claudino J.G., Mezêncio B., Soncin R., Ferreira J.C., Valadão P.F., Takao P.P., Bianco R., Roschel H., Amadio A.C., Serrão J.C. (2013) Development of an individualized familiarization method for vertical jumps. Rev. Bras. Med. Esporte, 19(4): 359-362. DOI: 10.1590/ S1517-86922013000500012.

10. Côrte A.C.R., Hernandez A.J. (2016) Application of medical infrared thermography to sports medicine. Rev. Bras. Med. Esporte, 22(4): 315-319. DOI: 10.5772/28383.

11. Cossenza C.E., Lima V.P. (2013) Musculaçăo: a prática dos métodos de treinamentos. 2Ş ed. Rio de Janeiro: Sprint.

12. Della Corte J., Paz G.A., Castro J.B.P., Miranda H. (2018) Hypotensive effect induced by strength training using the DeLorme and Oxford methods in trained men. Pol. J. Sport Tourism, 25(1): 23-30. DOI: 10.2478/pjst2018-0004.

13. Della Corte J., Pinheiro C.B., Lima B.L.P., Vignoli F.A., Oliveira, J.G.M., Castro J.B.P., Lima V.P. (2019) 
Thermographic analysis of the thigh of trained men submitted to the leg extension exercise. J. Phys. Educ. Sport, 19(4): 2458-2465. DOI: 10.7752/jpes.2019.04373.

14. Drakos M.C., Domb B., Starkey C., Callahan L., Allen A.A. (2010) Injury in the National Basketball Association: a 17-year overview. Sports Health, 2(4): 284-290. DOI: $10.1177 / 1941738109357303$.

15. Drinkwater E.J., Pyne D.B., McKenna M.J. (2008) Design and interpretation of anthropometric and fitness testing of basketball players. Sports Med., 38: 565-578. DOI: 10.2165/00007256-200838070-00004.

16. Fernández-Cuevas I., Sillero-Quintana M., GarcíaConcepción M.A., Serrano J.R., Gómez-Carmona P.M., Marins J.C.B. (2014) Monitoring skin thermal response to training with infrared thermography. New Studies in Athletics, 29(1): 57-71.

17. Fleck S.J., Kraemer W.J. (2017) Fundamentos do treinamento de força muscular. 4Ş ed. Porto Alegre: Artmed.

18. Gallardo-Fuentes F., Gallardo-Fuentes J., RamírezCampillo R., Balsalobre-Fernández C., Martínez C., Caniuqueo A., Cañas R., Banzer W., Loturco I., Nakamura F.Y., Izquierdo M. (2016) Intersession and intrasession reliability and validity of the My Jump App for measuring different jump actions in trained male and female athletes. J. Strength Cond. Res., 30(7): 2049-2056. DOI: 10.1519/JSC.0000000000001304.

19. Haynes T., Bishop C., Antrobus M., Brazier J. (2019) The validity and reliability of the My Jump 2 app for measuring the reactive strength index and drop jump performance. J. Sports Med. Phys. Fitness, 59(2): 253-258. DOI: $10.23736 / \mathrm{S} 0022-4707.18 .08195-1$.

20. Hester G.M., Pope Z.K., Sellers J.H., Thiele R.M., Freitas J.M. (2016) Potentiation: effect of ballistic and heavy exercise on vertical jump performance. $J$. Strength Cond. Res., 31(3): 660-666. DOI: 10.1519/ JSC.0000000000001285.

21. Horita T., Komi P.V., Hämäläinen I., Avela J. (2003) Exhausting stretch-shortening cycle (SSC) exercise causes greater impairment in SCC performance than in pure concentric performance. Eur. J. Appl. Physiol., 88(6): 527-534. DOI: 10.1007/s00421-002-0716-z.

22. Jaspers M.E.H., Carričre M.E., Meij-de Vries A., Klaessens J.H.G.M., Van Zuijlen P.P.M. (2017) The FLIR ONE thermal imager for the assessment of burn wounds: Reliability and validity study. Burns, 43(7): 1516-1523. DOI: 10.1016/j.burns.2017.04.006.

23. Jones P., Lees A. (2003) A biomechanical analysis of the acute effects of complex training using lower limb exercises. J. Strength Cond. Res., 17(4): 694-700. DOI: 10.1519/1533-4287(2003)017<0694:abaota $>2.0 . c o ; 2$

24. Komi P.V., Bosco C. (1978) Utilization of stored elastic energy in leg extensor muscles by men and women. Med. Sci. Sports., 10(4): 261-265.
25. Kraemer W.J., Ratamess N.A. (2004) Fundamentals of resistance training: progression and exercise prescription. Med. Sci. Sports. Exerc., 36(4): 674-688. DOI: 10.1249/01.mss.0000121945.36635.61.

26. Lewis M. (2018) It's a hard-knock life: game load, fatigue, and injury risk in the National Basketball Association. J. Athl. Train., 53(5): 503-509. DOI: 10.4085/10626050-243-17.

27. Liu C., Chen C.S., Ho W.H., Füle R.J., Chung P.H., Shiang T.Y. (2013) The effects of passive leg press training on jumping performance, speed, and muscle power. J. Strength Cond. Res., 27(6): 1479-1486. DOI: 10.1519/ JSC.0b013e31826bde9f.

28. Marchetti P.H., Uchida M.C. (2011) Influence of unilateral fatigue of lower limbs on the bilateral vertical jump. Rev. Bras. Med. Esporte, 17(6): 401-404. DOI: 10.1590/ S1517-86922011000600007.

29. Marfell-Jones M., Stewart A., Carter L. (2006) International standards for anthropometric assessment. South Africa, ISAK: Potchefstroom.

30. Marins J.C.B., Fernández-Cuevas I., Arnaiz-Lastras J., Fernandes A.A., Sillero-Quintana M. (2015) Aplicaciones de la termografía infrarroja em el deporte. Uma revisión. Revista Internacional de Medicina y Ciencias de la Actividad Física y del Deporte, 15(60): 805-824.

31. Meeusen R., Duclos M., Foster C., Fry A., Gleeson M., Nieman D., Raglin J., Rietjens G., Steinacker J., Urhausen A. (2013) Prevention, diagnosis, and treatment of the overtraining syndrome: joint consensus statement of the European College of Sport Science and the American College of Sports Medicine. Med. Sci. Sports Exerc., 45(1): 186-205. DOI: 10.1249/MSS.0b013e318279a10a.

32. Miranda H., Maia M.F., Paz G.A., Costa P.B. (2015) Acute effects of antagonist static stretching in the inter-set rest period on repetition performance and muscle activation. Res. Sports Med., 23(1): 37-50. DOI: 10.1080/15438627.2014.975812.

33. Miranda H., Simão R., Vigário P.S., Salles B.F., Pacheco M.T.T., Willardson J.M. (2010) Exercise order interacts with rest interval during upper body resistance exercise. J. Strength Cond. Res., 24(6): 1573-1577. DOI: 10.1519/ JSC.0b013e3181d8ea61.

34. Moreira D.G., Costello J.T., Brito C.J., Adamczyk J.G., Ammer K., Bach A.J.E., Costa C.M.A., Eglin C., Fernandes A.A., Fernández-Cuevas I., Ferreira J.J.A., Formenti D., Fournet D., Havenith G., Howell K., Jung A., Kenny G.P., Kolosovas-Machuca E.S., Maley M.J., Merla A., Pascoe D.D., Priego Quesada J.I., Schwartz R.G., Seixas A.R.D., Selfe J., Vainer B.G., Sillero-Quintana M. (2017) Thermographic imaging in sports and exercise medicine: a Delphi study and consensus statement on the measurement of human skin temperature. J. Therm. Biol., 69: 155-162. DOI: 10.1016/j.jtherbio.2017.07.006. 
35. Moreira D.G., Costello J.T., Brito C.J., Sillero-Quintana M. (2017) A checklist for measuring skin temperature with infrared thermography in sports and exercise medicine. Thermology International, 27(4): 141-143.

36. Naclerio F., Rodríguez-Romo G., Barriopedro-Moro M.I., Jiménez A., Alvar B.A., Triplett N.T. (2011) Control of resistance training intensity by the OMNI perceived exertion scale. J. Strength Cond. Res., 25(7): 1879-1888. DOI: 10.1519/JSC.0b013e3181e501e9.

37. Neto A.A., Pellegrinotti I.L., Montebelo M.I. (2006) Effects of a neuromuscular training program on the maximal Oxygen consumption and vertical jump in beginning volleyball players. Rev. Bras. Med. Esporte, 12(1): 29e-33e. DOI: 10.1590/S1517-86922006000100007.

38. Nogueira C. J., Galdino L.A.S., Vale R.G.S., Mello D.B., Dantas E.H.M. (2010) Acute effect of the proprioceptive neuromuscular facilitation method on vertical jump performance. Biomed. Hum. Kinet., 2: 1-4. DOI: 10.2478/ v10101-010-0001-2.

39. Oliveira S.A.F., Marins J.C.B., Silva A.G., Brito C.J., Moreira D.G., Sillero-Quintana M. (2018) Measuring of skin temperature via infrared thermography after an upper body progressive aerobic exercise. J. Phys. Educ. Sport, 18(1): 184-192.

40. Pasanen K., Ekola T., Vasankari T., Kannus P., Heinonen A., Kujala U.M., et al. (2017) High ankle injury rate in adolescent basketball: A 3-year prospective follow-up study. Scand. J. Med. Sci. Sports, 27(6): 643-649.

41. Paz G.A., Maia M.F., Lima V.P., Miranda H. (2014) Effect of agonist-antagonist method compared to traditional on muscular volume and activation. Rev. Bras. Ativ. Fis. Saúde, 19(1): 54-63. DOI: 10.12820/rbafs.v.19n1p54.

42. Paz G.A., Maia M.F., Lima V.P., Oliveira C.G., Bezerra E., Simão R., Miranda H. (2012) Maximal exercise performance and electromyography responses after antagonist neuromuscular proprioceptive facilitation: a pilot study. J. Exerc. Physiol. Online, 15(6): 60-67.

43. Quesada J.I.P., Carpes F.P., Bini R.R., Palmer R.S., Pérez-Soriano P., Anda R.M.C.O. (2015) Relationship between skin temperature and muscle activation during incremental cycle exercise. J. Therm. Biol., 48: 28-35. DOI: $10.1016 / \mathrm{j}$.jtherbio.2014.12.005.

44. Samozino P., Morin J.B., Hintzy F., Belli A. (2008) A simple method for measuring force, velocity and power output during squat jump. J. Biomech., 41(14): 29402945. DOI: 10.1016/j.jbiomech.2008.07.028.

45. Singh D., Singh S. (2012) Effects of vertical, horizontal, and combination depth jump training on long jump performance. Biomed. Hum. Kinet., 4: 107-111. DOI: 10.2478/v10101-012-0020-2.

46. Stasinaki A., Gloumis G., Spengos K., Blazevich A., Zaras N., Georgiadis G., Karampatsos G., Terzis G. (2015) Muscle strength, power, and morphologic adaptations after 6 weeks of compound vs. complex training in healthy men. J. Strength Cond. Res., 29(9): 2559-2569. DOI: 10.1519/JSC.0000000000000917.

47. Tillin N.A., Bishop D. (2009) Factors modulating postactivation potentiation and its effect on performance of subsequent explosive activities. Sports Med., 39(2): 147-166. DOI: 10.2165/00007256-200939020-00004.

\section{Received 14.01.2020 \\ Accepted 02.03.2020}

(C) University of Physical Education, Warsaw, Poland 